Original Article

\title{
IMPLICATIONS OF MOBILE PHASE COMPOSITION AND PH ON THE CHROMATOGRAPHIC SEPARATION OF AMITRIPTYLINE AND ITS METABOLITE NORTRIPTYLINE
}

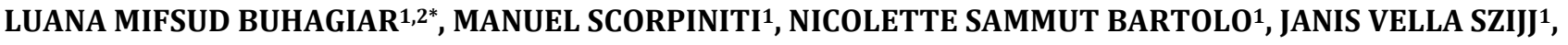 \\ VICTOR FERRITO ${ }^{1}$, ANTHONY SERRACINO INGLOTT ${ }^{1,2}$, GODFREY LAFERLA ${ }^{3}$
}

${ }^{1}$ Department of Pharmacy, Faculty of Medicine and Surgery, University of Malta, Msida, Malta, ${ }^{2}$ Malta Medicines Authority, Life Sciences Park, San Ġwann, Malta, ${ }^{3}$ Department of Surgery, Faculty of Medicine and Surgery, University of Malta, Msida, Malta

Email: luana.mifsud-buhagiar.06@um.edu.mt

Received: 17 Jan 2018 Revised and Accepted: 15 Mar 2018

\begin{abstract}
Objective: Separation of tricyclic compounds sets the keystone for determining parent drug to metabolite concentration ratios and analysing impurities. The combined effects of acetonitrile composition and $\mathrm{pH}$ of the mobile phase on the separation of amitriptyline and nortriptyline by
\end{abstract} reversed-phase high-performance liquid chromatography (RP-HPLC) are presented.

Methods: A series of RP-HPLC triplicate runs were carried out using acetonitrile and a phosphate buffer as the mobile phase and a Kinetex ${ }^{\circledR}$ C18 LC Column as the stationary phase using an Agilent 1260 Infinity Series ${ }^{\circledR}$ II liquid chromatography system with UV/visible detection. The stationary phase, column temperature, injection volume and flow rate were kept unchanged during analysis. Mobile phase composition and $\mathrm{pH}$ were varied to observe impact on peak shape, resolution and retention time, taking into consideration green analytical chemistry aspects.

Results: Optimal chromatographic outcomes were achieved when using the mobile phase made up of 35\% acetonitrile and $65 \%$ buffer at a $\mathrm{pH}$ of 5.6. These conditions resulted in nortriptyline and amitriptyline eluting at $4.66 \mathrm{~min}$ and $5.92 \mathrm{~min}$ respectively. Increasing the organic modifier content of the mobile phase to $40 \%$ completed separation within a run time of 4 min with comparable resolution. The 2 min gained by increasing $5 \%$ acetonitrile may not be justified due to potential implications on greening laboratory practices.

Conclusion: Reversed-phase chromatography embodies a simple method for the separation of compounds that are similar in structure. Attuning the percentage of organic modifier and buffer $\mathrm{pH}$ provides acceptable retention times, without compromising resolution between neighbouring peaks.

Keywords: RP-HPLC, Acetonitrile composition, pH, Amitriptyline, Nortriptyline

(c) 2018 The Authors. Published by Innovare Academic Sciences Pvt Ltd. This is an open access article under the CC BY license (http://creativecommons.org/licenses/by/4.0/) DOI: http://dx.doi.org/10.22159/ijpps.2018v10i4.24817

\section{INTRODUCTION}

Tricyclic antidepressants (TCAs) have been in clinical use for over fifty years and, owing to their efficacy and low cost, are still prescribed for the treatment of major depression and other psychiatric conditions as well as in bulimia, migraine prevention, neuropathic pain management, fibromyalgia, and enuresis [1, 2]. A limited number of analytical reports have focused on methodological considerations for chromatographic separation, with interest being fuelled thereafter by the recognition of the concentration-dependent effects of these narrow-therapeutic index drugs and the importance of testing formulations for quality assurance purposes. Modern-day methods for routine analysis of these drugs, their metabolites and potential impurities in pharmaceutical preparations and bio fluids are of paramount significance. High-performance liquid chromatography (HPLC) is the prevalent technique in published methods for the analysis of TCAs [3].

Amitriptyline, 3-(10,11-dihydro-5H-dibenzo [a, d] cyclohepten-5ylidene)-propyl dimethylamine, is a basic lipophilic drug, with a molecular weight of 277.39, made up of a hydrophobic skeleton and a basic tertiary amino group as the main functional group. The compound is practically insoluble in water as the free base. The salt, amitriptyline hydrochloride, is freely soluble in water and alcohol and easily dissolved in polar solvents such as acetonitrile [4]. Water solubility of amitriptyline hydrochloride is $\mathrm{pH}$-dependent with the highest solubility in an acidic environment. The solubility is significantly reduced when the protonation of the tertiary amino group is suppressed.

Amitriptyline has a pKa value of 9.4. At high $\mathrm{pH}$ values, amitriptyline is unionized, and the solubility is significantly reduced relative to a neutral aqueous solution. The tertiary amino group can provide ionic interactions with the silanol groups of the stationary phase. In reversed-phase high-performance liquid chromatography (RP-
HPLC), amitriptyline has a strong retention, and as most silica-based column packing materials should not be used in the basic environment, the working $\mathrm{pH}$ typically results in amitriptyline being chromatographed in cation form. Being very hydrophobic, a relatively high content of organic modifier is expected for the mobile phase. Amitriptyline absorbs UV light with the chromophore of the benzene ring being extended with the double bond in the side chain [5].

As a result of demethylation in the hepatic cytochrome P450 system, tertiary amines are metabolised to secondary amines, which have pharmacological activity. Nortriptyline, 3-(10, 11-dihydro-5H-dibenzo [a,d] cyclohepten-5-ylidene)-N-methyl-1-propanamine, a secondary amine with a molecular weight of 263.37, is the principal active metabolite of amitriptyline. Amitriptyline is one of the known impurities in nortriptyline preparations [6]. Amitriptyline and nortriptyline possess similar structures, mass and pKa values, making their separation difficult due to similar chromatographic behaviour. At a $\mathrm{pH}$ below the values of their pKas, the tricyclics are positively charged and interactions with silanol groups of the stationary phase may result in peak broadening and lack of selectivity and efficiency [7].

The physicochemical properties of molecules play a notable role in RPHPLC. Taking into account the characteristics of the analytes, various parameters may be modified to establish effective separation conditions. The type of buffer and organic modifier used and the $\mathrm{pH}$ of the mobile phase influence retention times, shape and resolution of analyte peaks [8]. In the case of analytes that can form ionised species, ionisation influences the distribution of the analyte between the mobile and stationary phases. Control of $\mathrm{pH}$, particularly through the buffering system in the mobile phase, largely determines the concentration ratio of protonated and unprotonated forms in the aqueous mobile phase and their distribution between the non-polar stationary phase and the polar mobile phase [9]. 
The purpose of this study was to develop a comparatively simple approach to investigate the combined effect of $\mathrm{pH}$ and acetonitrile composition on performing efficient separation of similar tricyclic compounds, without resorting to complex additives and resourceintensive settings. This paper details the approach adopted to identify the conditions for optimal separation which are presented through the chromatographic results and corresponding discussion.

\section{MATERIALS AND METHODS}

\section{Chemicals and reagents}

Amitriptyline hydrochloride and nortriptyline hydrochloride standards were procured from the European Directorate for the Quality of Medicines (EDQM). The structures of these compounds are shown in fig. 1 and fig. 2. Clomipramine hydrochloride standard was sourced from Sigma-Aldrich, Saint Louis, USA. Fisher Chemical, Leicestershire, UK supplied HPLC-grade water and orthophosphoric acid. Acetonitrile was acquired from Carlo Erba Reagents, Val-de-Reuil, France and disodium hydrogen phosphate from Scharlau, Sentmenat, Spain.

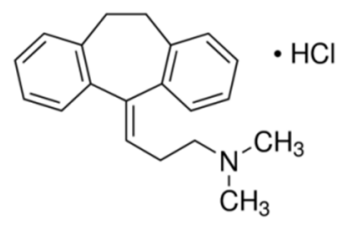

Fig. 1: Amitriptyline hydrochloride<smiles>CNCCC=C1c2ccccc2CCc2ccccc21</smiles>

Fig. 2: Nortriptyline hydrochloride

\section{Sample preparation}

Solutions of $100 \mu \mathrm{g} / \mathrm{ml}$ amitriptyline and nortriptyline were prepared in HPLC-grade water and mixed together by transferring $0.5 \mathrm{ml}$ of each solution into amber-coloured vials. Samples were stored at $4{ }^{\circ} \mathrm{C}$ until analysed.

\section{Mobile phases}

Mobile phases consisted of acetonitrile and phosphate buffer, which were degassed in an ultrasonic bath before use. The buffer solution was prepared by dissolving $5.23 \mathrm{~g}$ extra pure, anhydrous, disodium hydrogen phosphate in $1 \mathrm{~L}$ HPLC-grade water. The $\mathrm{pH}(4.4,5.6$ or 6.8) was adjusted by dropwise addition of HPLC-grade orthophosphoric acid. A Hanna ${ }^{\circledR}$ Bench-top pH meter HI8521 was calibrated using standard Hanna ${ }^{\circledR}$ calibrator buffer solutions (at $\mathrm{pH}$ values of 4.01 and 7.01) and used for $\mathrm{pH}$ measurements. Percentage acetonitrile composition was set at 30,35 or $40 \%$. Table 1 lists the nine different mobile phases used.

Table 1: Composition and $\mathrm{pH}$ of the different mobile phases investigated for the optimal chromatographic separation of amitriptyline and nortriptyline

\begin{tabular}{|c|c|c|c|c|c|c|c|c|c|}
\hline Mobile phase & 1 & 2 & 3 & 4 & 5 & 6 & 7 & 8 & 9 \\
\hline pH & 4.4 & & & \multicolumn{3}{|c|}{5.6} & \multicolumn{3}{|c|}{6.8} \\
\hline Percentage acetonitrile & 30 & 35 & 40 & 30 & 35 & 40 & 30 & 35 & 40 \\
\hline
\end{tabular}

\section{Analytical procedure}

An Agilent 1260 Infinity Series ${ }^{\circledR}$ II liquid chromatography system was employed for analysis. Amitriptyline and nortriptyline sample mixtures of $20 \mu \mathrm{l}$ were injected. Triplicate runs were performed for each mobile phase composition using a Kinetex ${ }^{\circledR}$ C18 LC Column $(150 \times 4.6 \mathrm{~mm}$; particle size $5 \mu \mathrm{m})$ at a temperature of $27{ }^{\circ} \mathrm{C}$. The mobile phase flow rate was set at $1 \mathrm{ml} / \mathrm{min}$. The UV wavelength was set at $210 \mathrm{~nm}$. Separate runs for pure amitriptyline hydrochloride and nortriptyline hydrochloride were first performed to assist with peak identification.

\section{Practical considerations}

Calibration in HPLC methods may require the use of an internal standard which is chemically similar to the targeted substances and can be completely separated from the peaks of other sample components. A $0.5 \mathrm{ml}$ aliquot of $100 \mu \mathrm{g} / \mathrm{ml}$ clomipramine hydrochloride solution, prepared by dissolving standard clomipramine hydrochloride powder in HPLC-grade water, was added to the amitriptyline and nortriptyline sample mixture. $20 \mu \mathrm{l}$ of the resulting mixture was injected into the same chromatographic system and mobile phase 5 (pH 5.6, acetonitrile 65:35 v/v) was employed to explore the implications of adding clomipramine for internal standardisation in the practical application of the method presented. A UV wavelength of $240 \mathrm{~nm}$ was also tested in this scenario.

\section{RESULTS AND DISCUSSION}

In the process of system configuration and optimisation of the set chromatographic conditions, methodical consideration was given to the properties of the stationary phase. A significant interaction between the compounds and HPLC column packing materials are common sources of peak tailing, asymmetry and low separation efficiencies [10]. The sodium or potassium salts of phosphoric acid are commonly used in buffer systems for RPHPLC. In general, no more than $50 \%$ organic solvent should be used in the mobile phase, depending on the concentration of the specific buffer employed. Methanol and acetonitrile are ordinarily employed as organic modifiers, with the latter being preferred in the scenario presented due to lower UV absorbance at the wavelength used for the analysis of the compounds of interest [11]. Other parameters were systematically assessed, experimenting with higher column temperatures, different injection volumes and flow rates, as well as dual UV wavelength. The conditions suitable for the purpose of the study were identified.

A change in the $\mathrm{pH}$ value is the principal tool to manipulate and optimise separation and selectivity for ionisable compounds. Additional considerations apply when observations from $\mathrm{pH}$ determined in aqueous systems are extrapolated to acetonitrileaqueous systems. Unlike the buffer capacity, the $\mathrm{pH}$ of a buffer changes upon the addition of an organic solvent and so do the pKa values. The combined effect of these shifts may yield important differences under the measurement conditions $[12,13]$. Changes in $\mathrm{pH}$ may also alter the position and intensity of UV absorption bands of molecules.

The working $\mathrm{pH}$ is preferably selected based on the type of buffer being used and according to the pKa values of the compounds. Alkaline pHs are not recommended for HPLC applications due to potential damage to the column through solubilisation of the silica support [14, 15]. Consequently, all mobile phases considered have $\mathrm{pH}$ values lower than the pKa value of the analytes. At $\mathrm{pH} 4.4$, chromatograms [fig. 3-5] showed limited separation and poor resolution, particularly mobile phases 2 and 3 . Significant improvement was observed at $\mathrm{pH} 5.6$ [fig. 6-8] while a $\mathrm{pH}$ of 6.8 prolonged the time for separation and resulted in undesirable peak shape [fig. 9-11]. 


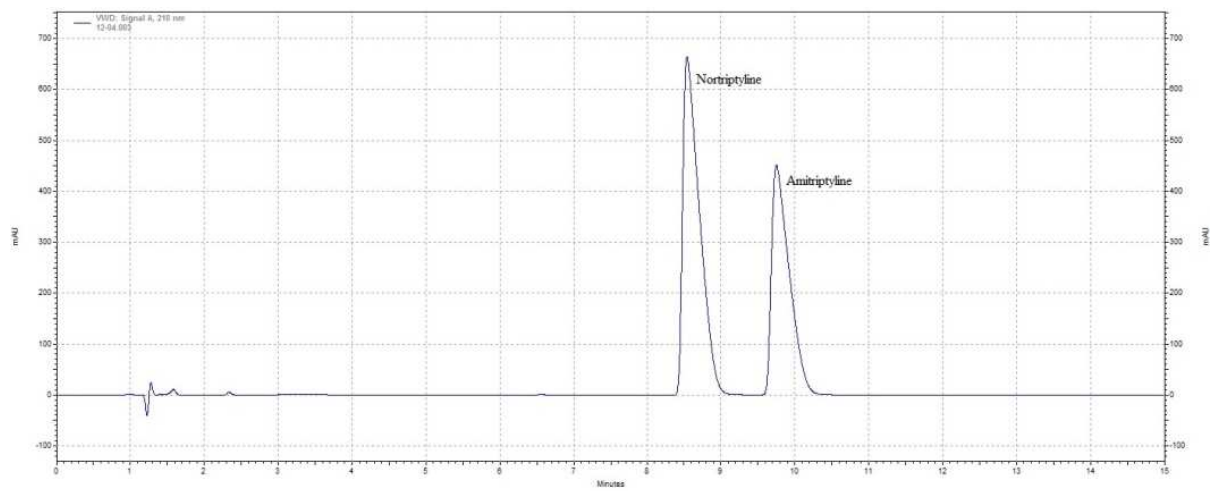

Fig. 3: Disodium hydrogen phosphate (pH 4.4) and acetonitrile (70:30 v/v)

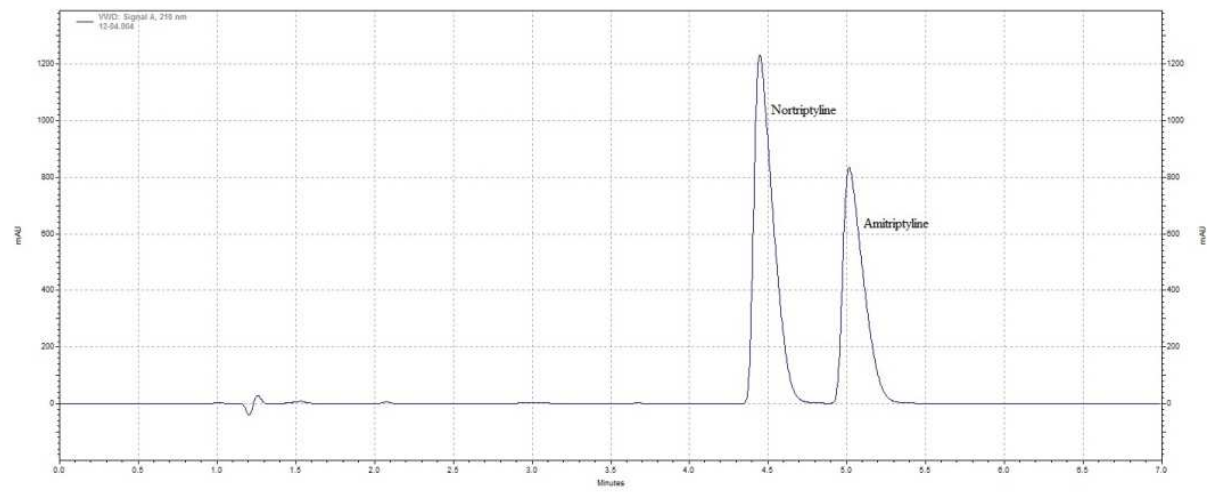

Fig. 4: Disodium hydrogen phosphate (pH 4.4) and acetonitrile (65:35 v/v)

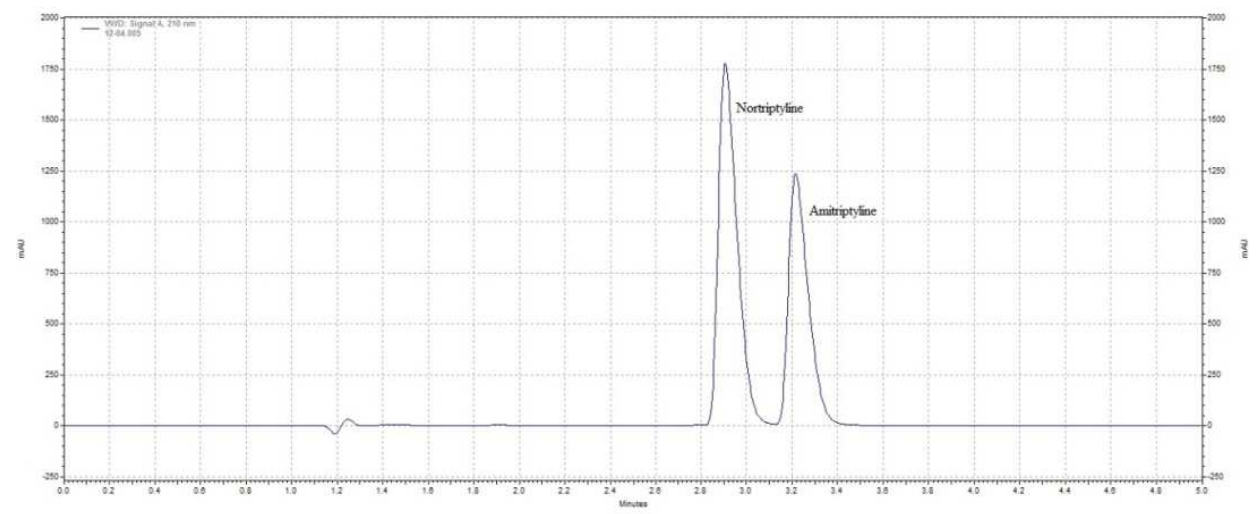

Fig. 5: Disodium hydrogen phosphate (pH 4.4) and acetonitrile (60:40 v/v)

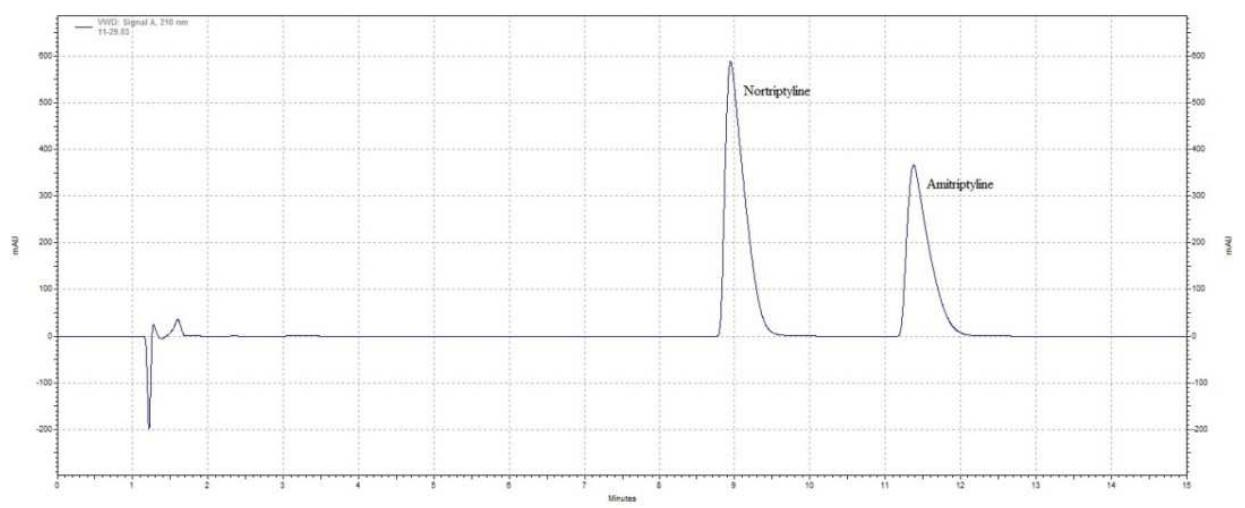

Fig. 6: Disodium hydrogen phosphate (pH 5.6) and acetonitrile (70:30 v/v) 


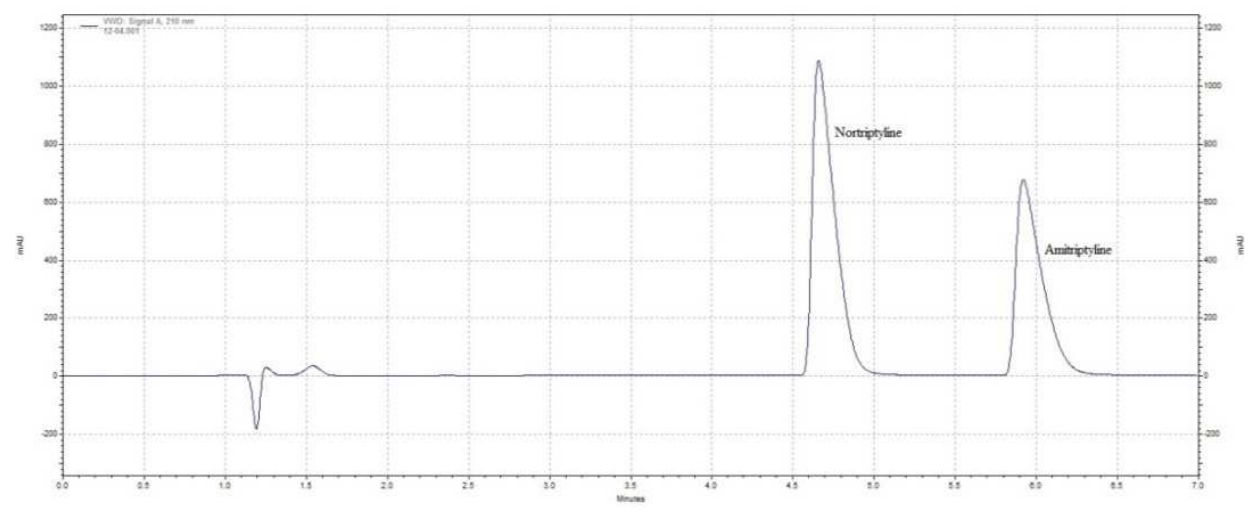

Fig. 7: Disodium hydrogen phosphate (pH 5.6) and acetonitrile (65:35 v/v)

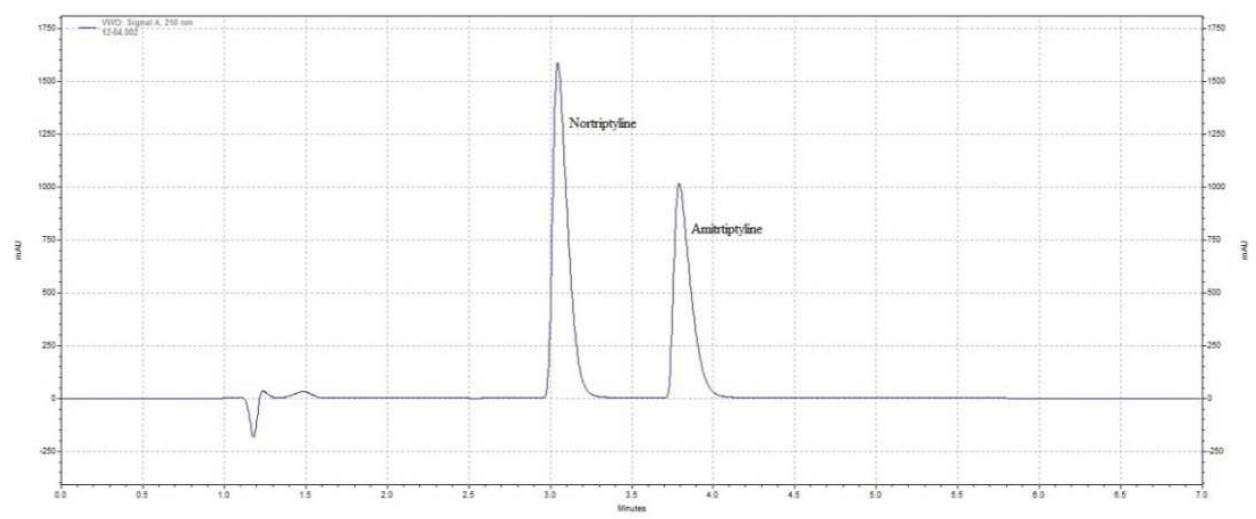

Fig. 8: Disodium hydrogen phosphate (pH 5.6) and acetonitrile (60:40 v/v)

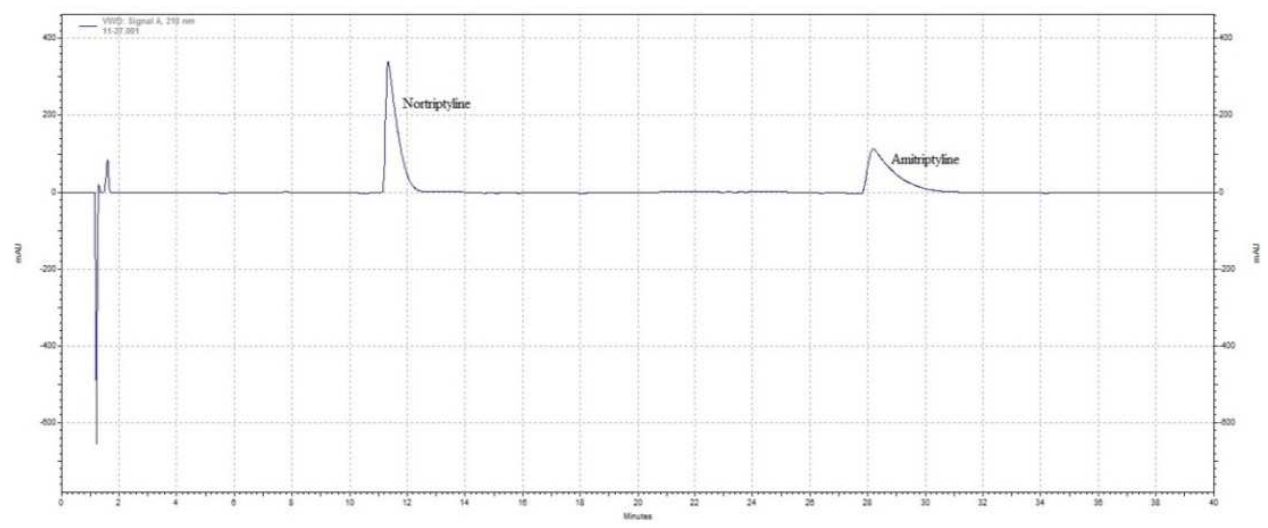

Fig. 9: Disodium hydrogen phosphate (pH 6.8) and acetonitrile (70:30 v/v)

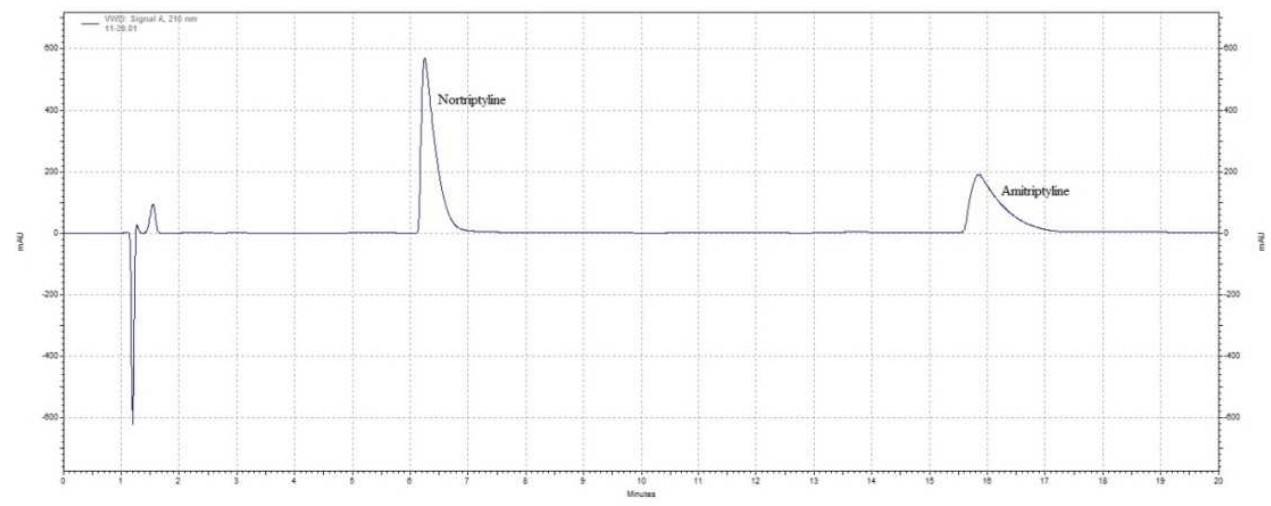

Fig. 10: Disodium hydrogen phosphate (pH 6.8) and acetonitrile (65:35 v/v) 


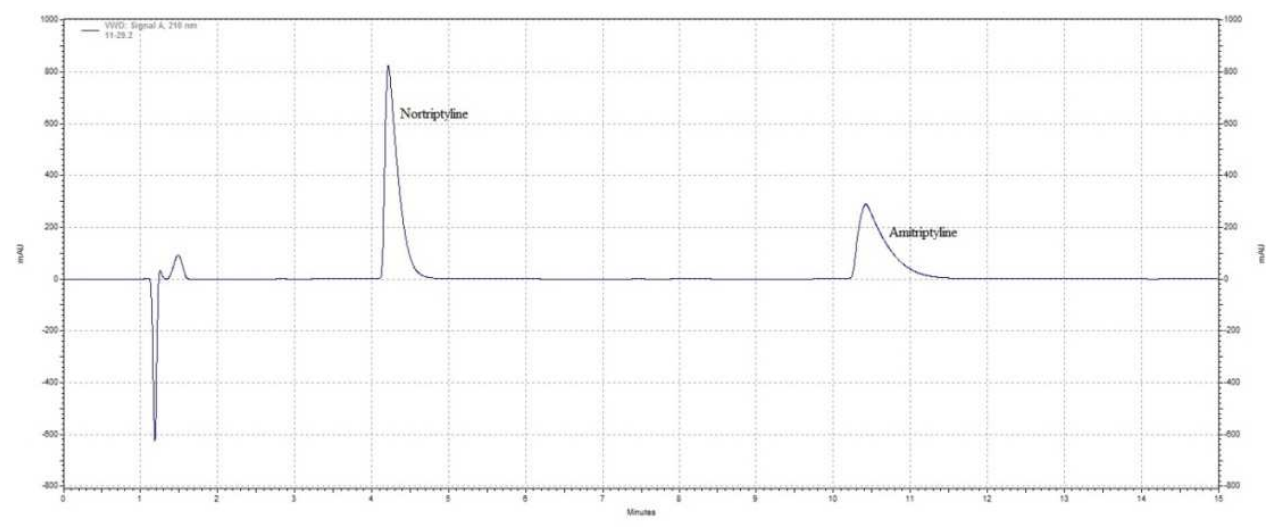

Fig. 11: Disodium hydrogen phosphate (pH 6.8) and acetonitrile $(60: 40 \mathrm{v} / \mathrm{v})$

Efficacy of separation is affected by $\mathrm{pH}$ which alters the relative proportion of ionised to non-ionised species in the mobile phase which in turn governs distribution between the stationary and mobile phases. Since the $\mathrm{pH}$ of the mobile phase with improved performance is $3.8 \mathrm{pH}$ units lower than the pKa of amitriptyline, the molecules are expected to be ionised $\left[\mathrm{R}-\mathrm{NH}^{+}\left(\mathrm{CH}_{3}\right)_{2}\right]$ in the buffer used, occurring predominantly in the protonated form [fig. 12]. Nortriptyline is similar in structure to amitriptyline and has a slightly higher pKa of 9.7. This similarity intensifies the challenge of determining isocratic conditions for the separation.

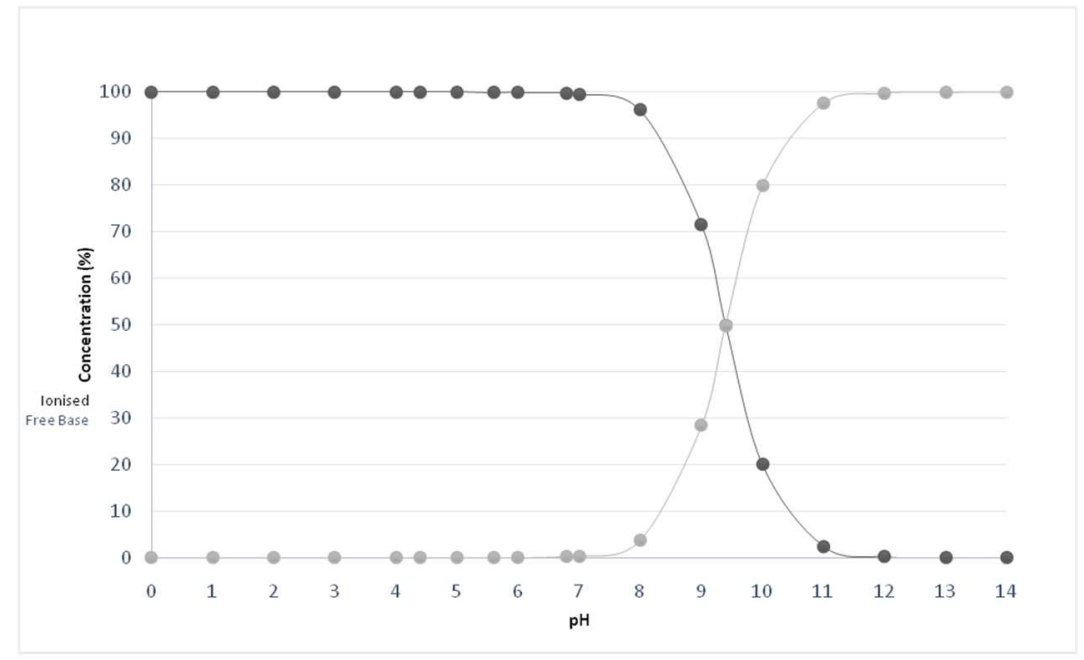

Fig. 12: Speciation plot for amitriptyline

Efficient separation can be achieved if a suitable blend of polar and less polar components makes up the mobile phase; this modifies the distribution coefficient for the partitioning of components between the stationary phase and the mobile phase [9]. In determining the amount of organic modifier, a content that is too low infers long retention times while opting for a high content leads to shorter retention times with decreased peak resolution. An increase in the percentage of acetonitrile decreased the retention of amitriptyline and nortriptyline. This may be explained by the competitive interaction of acetonitrile with the stationary phase, diminishing the interaction of amitriptyline and nortriptyline with the stationary phase. Reducing the amount of acetonitrile delayed the elution of amitriptyline, which was most evident at $\mathrm{pH}$ 6.8. Analysis at $\mathrm{pH} 4.4$ highlighted how increasing volumes of acetonitrile may result in decreased resolution between the two peaks. With all the different mobile phases used, nortriptyline eluted before amitriptyline.

More symmetrical peaks and less peak tailing were attained when using the mobile phase containing $35 \%$ acetonitrile at $\mathrm{pH} 5.6$ within a reasonable retention time for the separation of nortriptyline and amitriptyline (eluting at $4.66 \mathrm{~min}$ and $5.92 \mathrm{~min}$ respectively). Mobile phase 6 , with a composition of $40 \%$ acetonitrile, allowed for the complete separation of analytes within $4 \mathrm{~min}$ with comparable resolution. Fig. 13 shows how retention time decreased with increasing percentage of acetonitrile when using the mobile phase at $\mathrm{pH}$ 5.6. A mobile phase consisting of $35 \%$ acetonitrile was identified as the best compromise for the optimal separation of the compounds, as the analyte peaks were well defined and resolved at this composition. The chromatographic conditions described entail relatively low consumption of organic solvent and energy by operating around room temperature, supporting the progress towards green analytical chemistry to minimize the environmental impact.

In analytical RP-HPLC studies of amitriptyline and its metabolite nortriptyline, clomipramine characterizes a potential internal standard due to its chemical and physical similarity to the analytes of interest. Clomipramine, 3-(2-chloro-5,6-dihydrobenzo[b][1] benzazepin-11-yl)-N,N-dimethylpropan-1-amine, has a pKa of 9.2 . Adding a known amount of clomipramine may serve as a normalizing factor to compensate for losses and variability throughout the process. It is desirable that the internal standard elutes near to, but is well resolved from the calibrated compounds and is chromatographically distinguishable. Adequate separation of the three compounds was achieved under the identified chromatographic conditions. The chromatogram in fig. 14 shows separation using a UV wavelength of $240 \mathrm{~nm}$. Both amitriptyline and nortriptyline had a lower intensity of absorbance at this wavelength, compared to $210 \mathrm{~nm}$. 


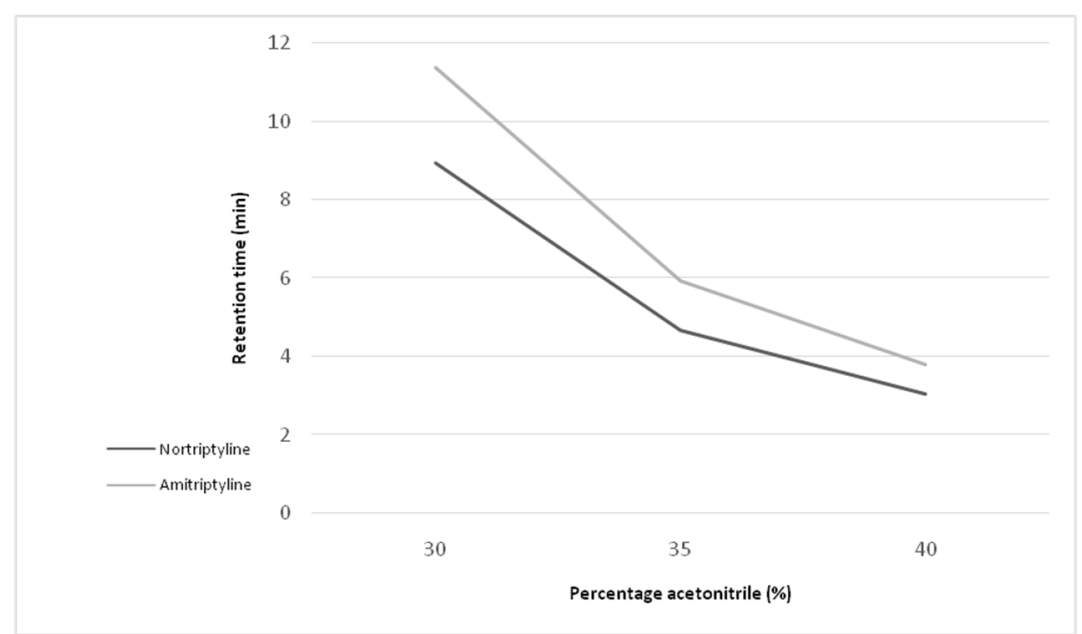

Fig. 13: Plots of the retention time vs. acetonitrile percentage in the mobile phase (pH 5.6)

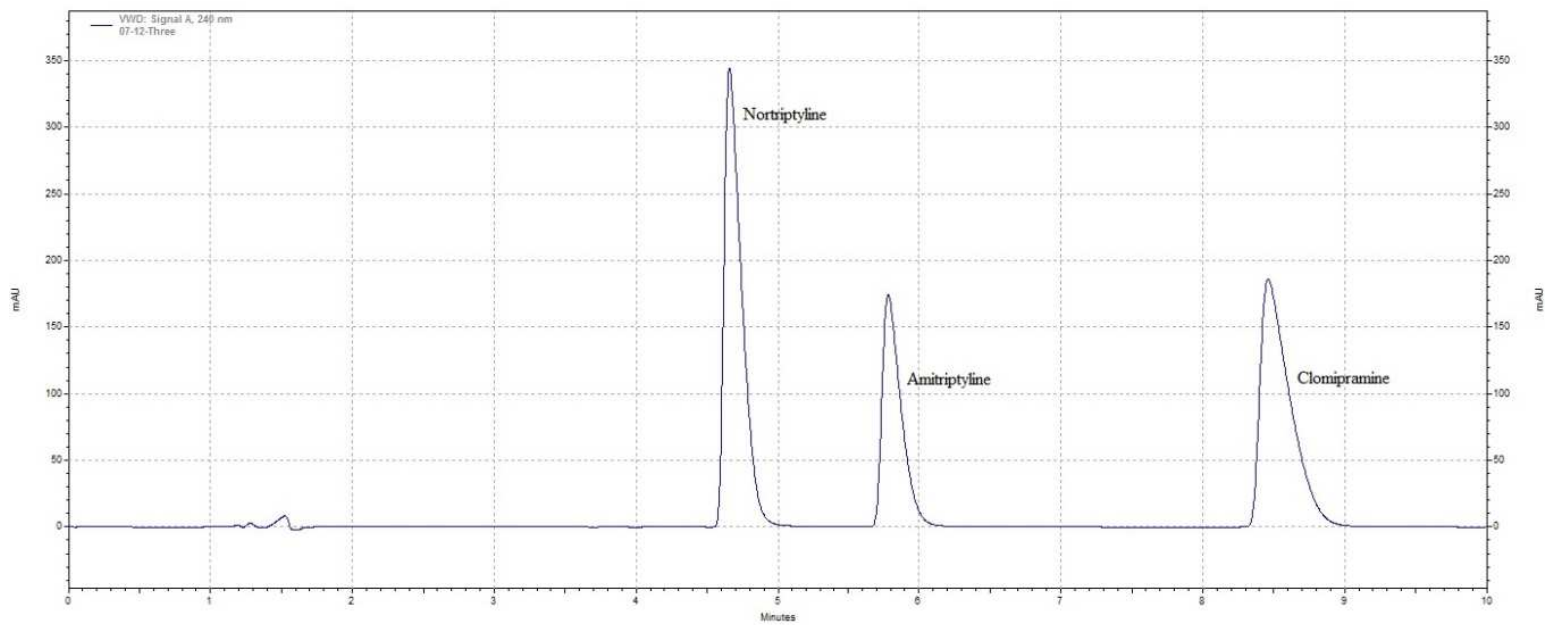

Fig. 14: Separation of amitriptyline, nortriptyline and clomipramine (pH 5.6; 35\% acetonitrile)

Literature related to the chromatographic separation of tricyclic compounds encompasses methods with column temperature varying from room temperature to $45^{\circ} \mathrm{C}$ and detection of analytes being performed mainly using ultraviolet or diode array detectors covering a range of wavelengths [2]. In RP-HPLC, retention times and resolution are effected by the underlying separation mechanism. The amount of organic modifier and $\mathrm{pH}$ of the buffer are critical parameters to achieve efficient methods of separation, resulting in quicker analysis and satisfactory results in reversed-phase chromatography [8-9, 16-17]. This study shows how these parameters can be modified concurrently to optimize separation of TCAs, without the inclusion of complex additives.

\section{CONCLUSION}

The rapid systematic technique presented in this paper scrutinises the combined effect of two major analytical parameters, buffer $\mathrm{pH}$ and mobile phase composition, which impact on the resolution of chromatographic peaks in the simultaneous separation of amitriptyline, nortriptyline and clomipramine. The mobile phase composed of phosphate buffer and acetonitrile in the ratio of 65:35 $(\mathrm{v} / \mathrm{v})$ at $\mathrm{pH} 5.6$ yielded the best compromise for the compounds of interest. With due consideration to the pertinent sample preparation procedures and ensuing validation, the proposed procedure is prospectively applicable to the analysis of pharmaceutical impurities and in pharmacokinetic studies, which are relevant when metabolite-to-parent drug concentration ratios are linked to potential variations in enzyme capacity and clinical events.

\section{ACKNOWLEDGEMENT}

The research work is funded by the ENDEAVOUR Scholarships Scheme. The authors thank Ms Rowena Calleja and Ms Claudine Micallef Peplow for laboratory support and technical assistance.

\section{AUTHORS CONTRIBUTIONS}

The corresponding author Ms. Luana Mifsud Buhagiar carried out the experimental work and data analysis with Mr. Manuel Scorpiniti, guided by Professor Victor Ferrito, Ms. Janis Vella Szijj and Ms. Nicolette Sammut Bartolo, under the supervision and critical review of Professor Anthony Serracino Inglott and Professor Godfrey LaFerla, within the Faculty of Medicine and Surgery at the University of Malta.

\section{CONFLICTS OF INTERESTS}

Declared none

\section{REFERENCES}

1. Dean L. Amitriptyline therapy and CYP2D6 and CYP2C19 genotype. In: Pratt V, McLeod H, Dean L, Malheiro A, Rubinstein W. editors. Medical Genetics Summaries [Internet]. Bethesda (MD): NCBI (US). Available from: https://www.ncbi.nlm.nih.gov/books/ NBK425165/. [Last accessed on 10 Dec 2017].

2. Seema AM, Chinchu J, Akhil B, Prudence AR. A prospective study on geriatric prescribing pattern and medication adherence in a tertiary care hospital. Asian J Pharm Clin Res 2017;10:220-5. 
3. Samanidou VF, Nika MK, Papadoyannis IN. HPLC as a tool in medicinal chemistry for the monitoring of tricyclic antidepressants in biofluids. Mini Rev Med Chem 2008;8:256-75.

4. Manzo RH, Olivera ME, Amidon GL, Shah VP, Dressman JB, Barens DM. Biowaiver monographs for immediate release solid oral dosage forms: amitriptyline hydrochloride. J Pharm Sci 2006; 95:966-73.

5. Hansen S, Pedersen Bjergaard S, Rasmussen K. Analytical chemical characteristics of selected drug substances. In: Introduction to pharmaceutical chemical analysis. $1^{\text {st }}$ ed. West Sussex: John Wiley and Sons, Ltd; 2012. p. 299-301.

6. ElHoussini OM, Zawilla NH. Chromatographic methods for the determination of fluphenazine, nortriptyline and its impurity amitriptyline in bulk and pharmaceutical formulations. J Anal Chem 2014;69:1187-92.

7. Dell'Aquila C. Separation of tricyclic antidepressants by capillary zone electrophoresis with $\mathrm{N}, \mathrm{N}, \mathrm{N}, \mathrm{N}$-tetramethyl-1,3butanediamine (TMBD) as an effective electrolyte additive. J Pharm Biomed Anal 2002;30:341-50.

8. Galaon T, David V. The influence of mobile phase $\mathrm{pH}$ on the retention and selectivity of related basic compounds in reversed-phase liquid chromatography. Rev Roum Chim 2012;57:131-40.

9. Vella J, Mifsud M, Sammut Bartolo N, Ferrito V, Serracino Inglott A, Azzopardi LM, et al. The combined effect of $\mathrm{pH}$ and acetonitrile composition on the separation of two lincosamide antibiotics. Asian J Pharm Clin Res 2014;7:96-100.
10. Ashour S, Kattan N. Simultaneous determination of nortriptyline hydrochloride and fluphenazine hydrochloride in microgram quantities from low dosage forms by liquid chromatography-UV detection. J Pharm Anal 2012;2:437-42.

11. Rao G, Goyal A. An overview on analytical method development and validation by using HPLC. Pharma Chem J 2016;3:280-9.

12. Subirats X, Roses M, Bosch E. On the effect of organic solvent composition on the $\mathrm{pH}$ of buffered HPLC mobile phases and the pKa of analytes-a review. Sep Purif Rev 2007;36:231-55.

13. Neue UD, Mendez A, Tran K, Diehl DM. pH and selectivity in RPchromatography. In: Kromidas S. editor. HPLC made to measure: a practical handbook for optimization. Weinheim: Wiley-VCH; 2006. p. 71-87.

14. Goeringer KE, McIntyre IM, Drummer OH. LC-MS analysis of serotonergic drugs. J Anal Toxicol 2003;27:30-5.

15. Kirkland JJ, Van Straten MA, Claessens HA. High pH mobile phase effects on silica-based reversed-phase high-performance liquid chromatographic columns. J Chromatogr A 1995;691:3-19.

16. Berges R, Sanz-Nebot V, Barbosa J. Modelling retention in liquid chromatography as a function of solvent composition and $\mathrm{pH}$ of the mobile phase. J Chromatogr A 2000;869:27-39.

17. Espinosa S, Bosch E, Roses M. Retention of ionizable compounds in high-performance liquid chromatography 14. Acid-base $\mathrm{pK}$ values in acetonitrile-water mobile phases. J Chromatogr A 2002;964:55-66. 